\title{
Modification of Carbon Nanotubes with Cadmium Sulfide Quantum Dots to Obtain Electrode Materials for Current Sources
}

\author{
M.O. Danilov*, G.Ya. Kolbasov \\ V.I. Vernadskii Institute of General and Inorganic Chemistry of the Ukrainian National Academy of Sciences, Kyiv, Ukraine \\ *Corresponding author: danilovmickle@ rambler.ru
}

Received December 29, 2012; Revised May 01, 2013; Accepted May 10, 2013

\begin{abstract}
It has been shown by the modification of multiwalled carbon nanotubes with cadmium sulfide quantum dots that nanocomposites based on multiwalled carbon nanotubes with monitored size of deposited cadmium sulfide nanoparticles can be fabricated. It has been shown that carbon nanotubes modified with CdS quantum dots are good catalysts for the oxygen electrodes of low-temperature fuel cells. The size of CdS nanoparticles was monitored by absorption spectra of a colloidal solution. The proposed method can be employed to fabricate nanocomposites from carbon nanotubes and semiconductor catalysts.
\end{abstract}

Keywords: carbon nanocomposites, CdS quantum dots, catalysts, electrocatalysis, electrochemical power sources

\section{Introduction}

The use of air or oxygen electrode in devices generating electrical energy is very promising since it does not give rise to environmental problems and makes it possible to save natural resources, such as oil and gas. Oxygen electrode is a three-phase electrode- electrolyte-gas system, where the electric current generation processes are localized at the interface between these phases. It consists of a catalyst and a support, the interaction between which determines the value of generated current. Literature shows that thanks to their structure and properties, carbon nanotubes [1,2] are the most efficient catalyst supports. Carbon nanotubes (CNTs), one of the allotropes of carbon are hollow cylindrical structures formed by rolling of graphene sheet with $\mathrm{sp}^{2}$ and $\mathrm{sp}^{3}$ bonding. Circular curvature causes quantum confinement and $\sigma-\pi$ rehybridization with three $\sigma$ bonds out of plane and $\pi$ orbitals delocalized outside the tube, which gives them most interesting properties like high mechanical strength, high thermal and electrical conductivity. The length of the tube can be several hundred times more than its width, which gives CNTs a high aspect ratio. Multiwalled carbon nanotubes (MWCNTs) consists of large number of concentric cylinders of graphene of length several micrometers and distance between neighbouring shells equal to interlayer spacing of graphene sheets i.e. $0.34 \mathrm{~nm}$. CNTs are highly attractive for research due to their remarkable properties like small size, very high mechanical strength, high strength to weight ratio, high transport coefficient which makes them appropriate candidate for different applications. Due to its highly desirable properties, CNTs have profound applications such as catalyst support materials for different types of fuel cells. CVD methods, electrochemical and chemical methods for the fabrication of composites based on nanotubes and catalysts were proposed [3,4,5]. However, not all of these methods enable one to deposit catalyst nanoparticles of definite size onto supports. The most suitable method, in our opinion, is modification of carbon nanotubes with quantum dots of semiconductors or metals, which allows one to obtain oxide or sulfide catalysts with controllable particle size. Chalcogenides have been known as the most potent photocatalyst candidates working under visible light. The use of cadmium sulfide as the catalyst for the oxygen electrode is not described. So it was interesting to investigate the catalyst in the mockup for the testing of gas-diffusion electrodes. The size of semiconductor nanoparticles at the moment of deposition onto the support can be monitored by absorption spectra of colloidal solutions using standard quantum-chemical calculations. The particle size can be varied by changing the catalyst concentration in the solution and selecting appropriate stabilizer for the existence of colloidal solution.

\section{Experimental}

Multiwalled carbon nanotubes (MWCNT), which are fabricated by the catalytic pyrolysis of ethylene on a catalyst, were used as catalyst support [6]. It was a powder with a bulk density of $25-30 \mathrm{~g} / \mathrm{dm}^{3}$. The outside diameter of nanotubes was about $10-30 \mathrm{~nm}$, the specific surface area was $230 \mathrm{~m}^{2} / \mathrm{g}$. CdS particles were deposited in subacid aqueous-alcoholic solutions. Dilute solutions of $\mathrm{Na}_{2} \mathrm{~S}$ $(0.05 \mathrm{~mol} / \mathrm{L})$ and $\mathrm{CdCl}_{2}(0.05 \mathrm{~mol} / \mathrm{L})$ were brought to $\mathrm{pH}=$ 2 with sulfuric acid. To obtain nanosized particles in colloid, 5\% polyvinyl alcohol as a stabilizer was added during pouring the solutions together. The size of $\mathrm{CdS}$ 
particles produced in the colloidal solution was determined by absorption spectra.

Two-layer oxygen electrodes were fabricated by pressing. The hydrophobic layer contained $0.07 \mathrm{~g} / \mathrm{cm}^{2}$ acetylene black with $25 \%$ polytetrafluoroethylene, and the active layer contained $0.02 \mathrm{~g} / \mathrm{cm}^{2}$ multiwalled nanotubes, modified with different catalysts, with $5 \%$ polytetrafluoroethylene. The mockup for the testing of gas-diffusion electrodes is shown in Figure 1.The electrolyte was an analytically pure $6 \mathrm{M} \mathrm{KOH}$ solution.

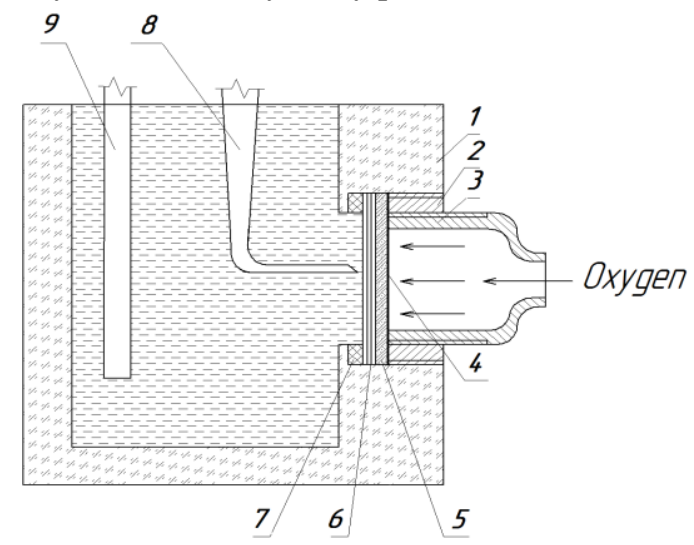

Figure 1. Scheme of the cell: (1) cell body, (2) clamping coupling, (3) metallic current tap and oxygen supply tube, (4) metallic net of the oxygen electrode, (5) hydrophobic layer of the oxygen electrode, (6) active layer of the oxygen electrode, (7) polytetrafluoroethylene gasket, (8) reference electrode, (9) zinc anode

Zinc was used as the auxiliary electrode. For all investigations, the reference electrode was a silverchloride electrode connected through a salt bridge. All potentials are given versus the silver-chloride reference electrode. The electrochemical curves were recorded under galvanostatic conditions. The oxygen source was a U-shaped electrolyzer with alkaline electrolyte. Oxygen was supplied to the gas electrodes under an excess pressure of $0.01 \mathrm{mPa}$. Before operation, the oxygen electrode was blown down with oxygen during an hour. The deposited cadmium sulfide was identified by X-ray fluorescence analysis by means of an ELVAX SBR-01 Xray energy spectrometer. The electron micrographs have been obtained by means of a JEM-100 CXII electron microscope.

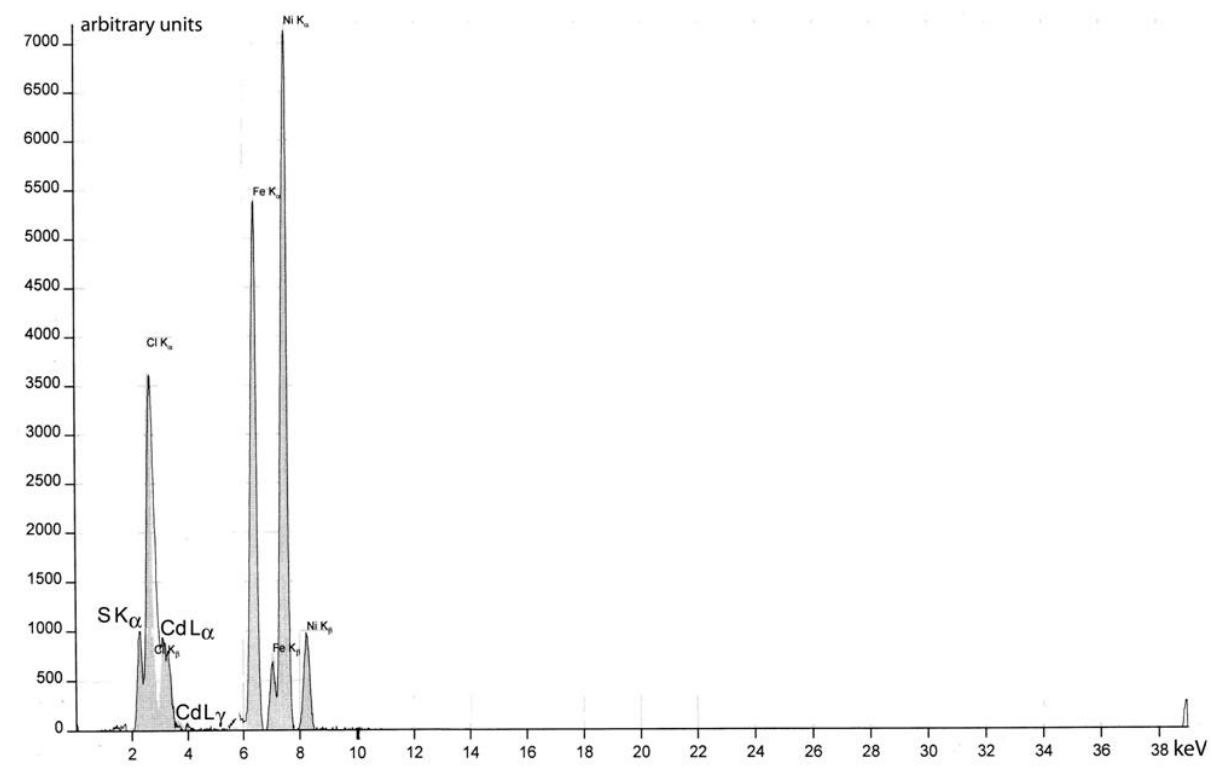

Figure 3. Spectrum of a nanocomposite deposited onto carbon nanotubes

\section{Results and Discussion}

The dependence of optical density on wavelength is shown in Figure 2. Since $\mathrm{CdS}$ is a semiconductor in which direct band-toband optical transitions are observed [7], the energy gap width $\mathrm{E}_{\mathrm{g}}$ was determined by commonly used procedures as a tangent in the absorption spectrum at the inflection points of the curve from the relation $(\mathrm{Dh} v)^{2} \approx \mathrm{h} v$ up to the value $\mathrm{Dh} v=0$. The particle size was determined from the optical energy gap width $\mathrm{E}_{\mathrm{g}}$. semiconductor particles in the region of steep rise of the plot of $\mathrm{D}(\lambda)$ by quantum-chemical calculations described in $[8,9]$. For $\mathrm{CdS}$ particles, the values of $\mathrm{E}_{\mathrm{g}}$ were determined in two spectral regions, and the values for particles of two sorts have been determined: $\mathrm{E}_{\mathrm{gl}}=2.49-2.53 \mathrm{eV}$, which values correspond to large particles $(\mathrm{D}>10 \mathrm{~nm})$, and $\mathrm{E}_{\mathrm{g} 2}=2.70-2.95 \mathrm{eV}$ at a particle diameter of $2 \mathrm{~nm}$. Samples of MWCNTs were dipped into a solution after the necessary optical density for the fabrication of $2 \mathrm{~nm}$ particles had been reached and held for 30 minutes; then they were dried at $90^{\circ} \mathrm{C}$ and washed. This procedure was repeated several times to obtain different amounts of deposited cadmium sulfide. Cadmium and sulfur peaks have been found, which corroborates deposition of cadmium sulfide on nanotubes. The deposited cadmium sulfide was identified by X-ray fluorescence analysis. Figure 3 shows the spectrum of a nanocomposite deposited onto carbon nanotubes.

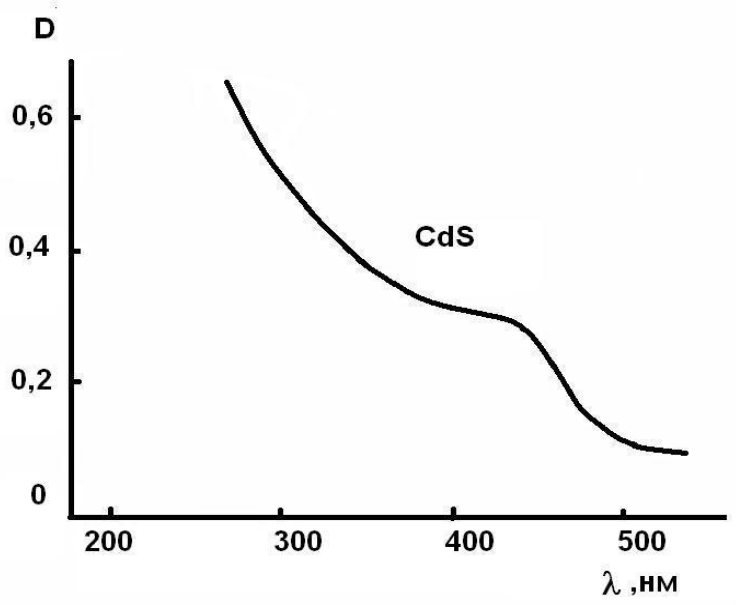

Figure 2. Spectral dependence of the optical density D of a colloidal solution on wavelength for CdS particles. Thickness of quartz cell: $10 \mathrm{~nm}$ 
The elemental cadmium content has been determined by spectral analysis to be $1,2,4$ and $7 \mathrm{wt} \%$. Figure 4 shows micrographs of a nanocomposite with a cadmium content of $4 \mathrm{wt} \%$ and Figure $54-7 \mathrm{wt} \%$ of cadmium content. The size of particles deposited onto carbon nanotubes allows one to assert that they were modified with cadmium sulfide quantum dots. Oxygen electrodes have been fabricated from the samples obtained of MWCNTs with deposited cadmium sulfide. Figure 6 shows electrical characteristics of oxygen electrodes based on carbon nanotubes modified with cadmium sulfide quantum dots. For comparison, this figure shows current density - potential curves for electrodes based on carbon nanotubes treated with sodium sulfide (Figure 6, curve 1) and electrodes based on carbon nanotubes with deposited metallic platinum (Figure 6, curve 6).

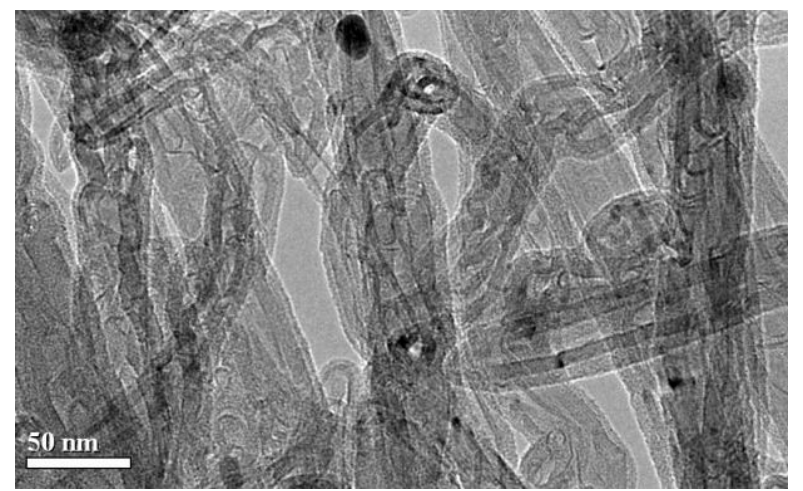

Figure 4. Micrograph of a nanocomposite based on MWCNTs mofdified with cadmium sulfide quantum dots with a catalyst particle size of up to $10 \mathrm{~nm}$

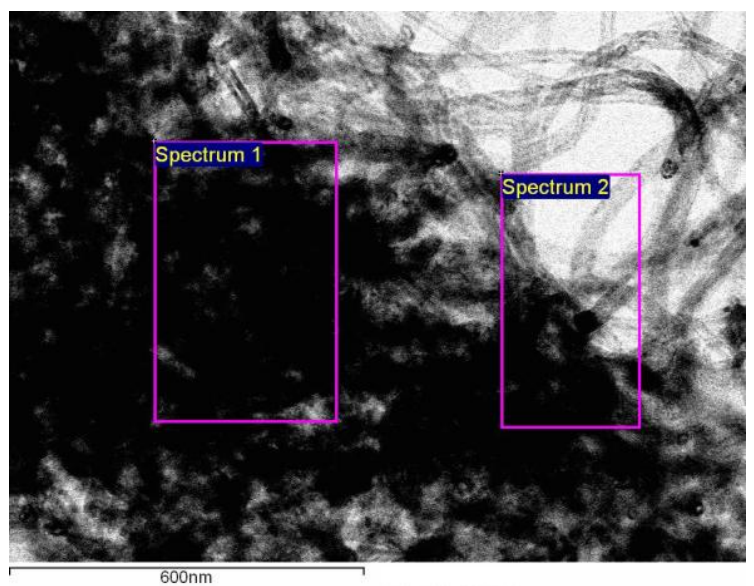

Figure 5. Micrograph of a nanocomposite based on MWCNTs mofdified with cadmium sulfide, containing $7 \mathrm{wt} \%$ elemental cadmium, with a particle size of about $60 \mathrm{~nm}$

As is seen from Figure 6, the characteristics of oxygen electrodes based on carbon nanotubes modified with cadmium sulfide quantum dots (Figure 6, curve 5) approach those of platinum-based oxygen electrodes. When the amount of cadmium sulfide deposited onto nanotubes is increased, an increase in characteristics is observed at first (Figure 6, curves 3-5); then a decrease in characteristics with increase in the amount of cadmium to $7 \mathrm{wt} \%$ is observed, which may be due to the formation of large agglomerates of deposited catalyst, as is seen from the micrograph in Figure 5. Comparison with electrodes based on MWCNTs with deposited $1 \mathrm{wt} \%$ metallic platinum (Figure 6, curve 6) shows that carbon nanotubes modified with cadmium sulfide quantum dots are a promising material for oxygen electrodes. A test of the oxygen electrodes obtained for the stability of characteristics in time showed the electrical characteristics to be stable during three months long operation. Calculated electrochemical characteristics of the oxygen electrode of power cell based on multiwalled carbon nanotubes modified with cadmium sulfide quantum dots are $280 \mathrm{~mW} \mathrm{~cm}^{-2}$ with the polarization of $250 \mathrm{mV}$ at room temperature.

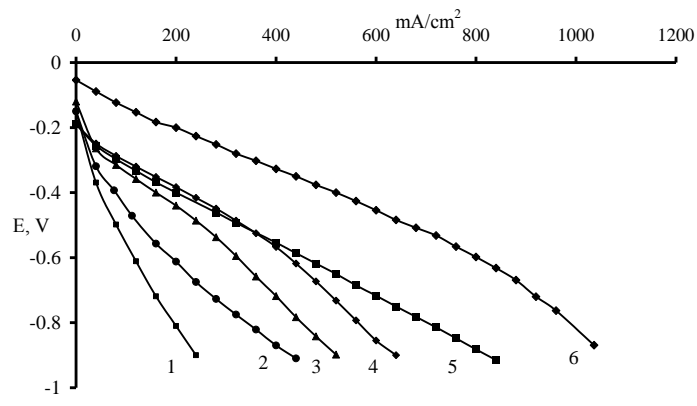

Figure 6. Dependence of potential on current density for oxygen electrodes based on nanocomposites of MWCNTs with deposited 0.02 $\mathrm{g} / \mathrm{cm}^{2}$ cadmium sulfide containing elemental cadmium (wt\%): (1) pure MWCNTs treated with sodium sulfide, (2) 7 , (3) 1, (4) 2, (5) 4, (6) MWCNTs with $1 \mathrm{wt} \%$ metallic Pt

\section{Conclusions}

It has been found that the modification of carbon nanotubes with quantum dots of catalysts based on semiconducting materials is a promising method for the controlled synthesis of composites for the electrodes of electrochemical power sources.

\section{References}

[1] Soehn M., Lebert M., Wirth T., Hofmannc S., Nicoloso N., "Design of gas diffusion electrodes using nanocarbon", Journal of Power Sources, 176, 494-498. 2008.

[2] Wu Z. P., Xia B. Y., Wang X. X., Wang J. N.,'Preparation of dispersible double-walled carbon nanotubes and application as catalyst support in fuel cells", Journal of Power Sources, 195, 2143-2148. 2010.

[3] Danilov M. O., Melezhyk A.V., "Carbon nanotubes modified with catalyst-promising materials for fuel cells", Journal of Power Sources, 163, 376-381. 2006.

[4] Neburchilov V., Wang H., Martin J. J., Qu W., "A review on air cathodes for zinc-air fuel cells", Journal of Power Sources, 195, 1271-1291. 2010.

[5] Yan J., Zhou H., Yu P., Su L., Mao L., “A general electrochemical approach to deposition of metal hydroxide/oxide nanostructures onto carbon nanotubes", Electrochemistry Communications, 10, 761-765. 2008.

[6] Melezhik A. V., Sementsov Yu. I., Yanchenko V. V., "Synthesis of fine carbon nanotubes on coprecipitated metal oxide catalysts", J. of Applied Chem. (Russian), 78 (6), 917-923. 2005.

[7] Pleskov Yu. V., Gurevich Yu. Ya., Semiconductor Photoelectrochemistry, Plenum Press, New York, 1986.

[8] H. Weller, M. H. Schmidt, U. Koch et al, "Photochemistry of colloidal semiconductors: Onset of light absorption as a function of size of extremely small CdS particles." Chem Phys. Lett., 124, 557-560. 1986.

[9] Kamat P. V., "Photochemistry on nonreactive and reactive (semiconductor) surfaces", Chem. Rev., 93 (1), 267-300. 1993. 